\title{
ACERCA DE TERMOS PARA DINHEIRO
}

Ha sesenta anos editava o jornal $A \mathrm{Voz}$ um interessante suplemento infantil denominado $O$ Tiroliro, cujo director se ocultava sob o nome de tio Tiroliro.

Em 27 de Agosto de 1939, ano XI da sua publicação, em o número 525, página 5, vem uma útil e curiosa lista que apresenta alguns sinónimos da palavra dinheiro, subscrito por um tal Zé e intitulado Auxiliar das "Lecas".

Começamos este breve artigo dando por ordem alfabético, como lá vem o referido do elenco. Os vocábulos, assim lá afirmam, não constituem "a sua totalidade, más são possivelmente a maior parte".

A: ajuda, arame, argem, arroz. B: bagaço, bagarota, bagarote, bagalhoça, bago, baguines, bagumes, bala, bens, bicos, bilhestres, bolsinho, bolo, boro, boros, brança, broça, brocha, bronze, bungo. C: cabedal, cabedais, cacao, cação, cacau, calica, calique, caroço, chapa, chelpa, china, chocalhinho, chorame, chorume, cobre, conquibos, conquitus, coragem, coscorilho, cóscos, cunques, cuques. D: deeiro, dote. E: economias, espada, espécie. F: fazenda, ferro, fio. G: gadé, gimbo, gorgeta, guines. J: Jan da Cruz, João da Cruz, jibungo, jimbongo, jumbugo. L: lecas, lega. M: maco, maquia, marca, massa, melgueira, metal, milho, miúdos, moapa, moeda, moni, môsca, música. N: nota, notas, numerário, numo, nuto. O: oiro, ouro. P: painso, palhaços, parne, pastor, pataco, patacos, patakia, pataquia, patarra, paus, pé de meia, pecúlio, pecúnia, pecuniarda, perezil, pesante, pinto, portuguesa, prata. Q: quantia, quatrini. R: riqueza, roço. S: sapequas, sapiquas, sepiquas. T: teca. V: vintém. Y: zerzulho, zimbo.

Vamos agora procurar alguns comentários a estes "sinónimos de dinheiro", sugeridos pela nossa experiência de pessoa nada e criada em Lisboa, desde há já quase oitenta anos.

$\mathrm{Na}$ letra $\mathrm{A}$, compreende-se ajuda, mas nunca ouvimos o termo neste sentido, embora seja justificável. Temos vaga idea de arame, em calão. Argem é, naturalmente, um aportuguesamento do francês argent. De arroz para dinheiro náo nos lembramos. Em $\mathrm{B}$ parece-nos ter visto bagaço, mas não bagarota ou bagarote. Já bagalhoça era corrente, bem como bago. Baguines ou bagumes nada nos dizem, e tem assim bala, bicos, bilhestres, brança, broça ou brocha e bungo. Bem é muito usual, mas, tal como bolsinho, sinónimo de dinheiro nunca nos constou, bolo compreende-se, e boro/boros são com certeza a sua deturpação. Bronze achamos nunca ter ouvido, mas entende-se perfeitamente, visto haver muitas moedas nesta liga metálica. No $C$ cabedal/cabedais eram vulgares, mas cacau dizia-se apenas em calão, e nunca ouvimos cacao, que é o termo francês talvez proferido por alguns. Cabica/cabique não são do nosso conhecimento, bem como china. Caroço era bastante popular, chapa e chelpa pertencem ao calão; chocalhinho é fácil de perceber (como diminutivo de chocalho), todavia jamais o lemos nem ouvimos, chorame e chorume têm significado evidente, por extensão de sentido, 
porém nunca nos surgiu em qualquer nível de linguagem. De cobre recordamo-nos só no plural, e a significação é claríssima, dado que durante a República grande parte das moedas têm sido neste metal. Conquibos/conquíbus ouvia-se muito: deve-se à adaptação do latim cum quibus "com os/as quais", subentendendo-se moedas ou notas de banco. Julgamos que os vocábulos cunques e cuques, nossos desconhecidos, são, por sua vez, deturpação dos anteriores. Coragem para dinheiro não nos ocorre, e também ignoramos coscorilho e coscos. Na letra $\mathrm{D}$, deeiro é claramente alteração infantil ou brincalhona de dinheiro (melhor seria escrever dieiro). No $\mathrm{E}$, toda a gente sabe que economia se refere a dinheiro, mas não era costumeiro o seu emprego como termo sinónimo deste, em todos os níveis linguísticos. Espada, com tal valor, é para nós inteiramente novidade. Em compensação, espécie é palavra usada extremamente ainda hoje, sobretudo na locução financeira em espécie (isto é, em dinheiro vivo, não em cheques, letras ou promissórias). No $\mathrm{F}$ só fazenda nos é conhecido, mas tal como economias, não tinha uso corriqueiro como sinónimo de dinheiro. Ferro e frio são-nos completamente estranhos no significado que nos interessa. Em G, só gorgeta (mesmo assim apenas a significar gratificação) é do conhecimento geral; os outros três termos devem ser de "puro" calão, empregado em certos meios. Igualmente, na letra $\mathrm{J}$, nunca escutámos João da Cruz e suas variantes. No L, lecas ainda na actualidade é razoávelmente usado, e lega talvez constitua a sua desvirtuação. Máquia é vocábulo bastante utilizado, sobretudo na expressão grossa máquia, por muito dinheiro. Maca (desfiguração de máquia?) nunca por nós foi ouvido ou lido. Marca, mosca e música não os conhecemos como sinónimos de dinheiro. Massa é extremamente habitual em nossos dias. Melgueira é outro vocábulo ignorado, pelo menos para nós. Metal emprega-se especialmente na expressão o vil metal, depreciativa de dinheiro, que dantes nunca era em notas. Milho também é muito frequente. Miúdos emprega-se para exprimir "trocos, dinheiro trocado". Miopa é um ilustre desconhecido. Moeda, o termo mais frequente a seguir a dinheiro (dentro desse sector, claro está) não é afinal sinónimo de dinheiro, a não ser na expressão papel moeda = nota de banco. Móni, antigamente muito popular, é o aportuguesamento do inglês money, como não se ignora. N: Nota e notas são palavras mais que óbvias e bastante usuais, bem como numerário, mais erudita. Nunca nos deparámos com numo, mas o étimo latino, numus, é mais que evidente. Já nuto nada nos diz.

$\mathrm{Na}$ letra $\mathrm{O}$, oiro, hoje menos vulgar que ouro, embora mais moderno, é sinónimo muito lato, que evoca os bons tempos das moedas de ouro, que ainda antes do fim da monarquia, portanto em fins do século XIX, deixaram de se fabricar. Na letra $P$, painço, nunca o ouvimos, ao contrário, como dissemos, de milho, seu parente mais graúdo e menos antigo. Palhaços é muito vulgar, familiar, mas não exprime propriamente dinheiro, mas escudos, por exemplo na frase isto custou 150 palhaços. Parne, pastor, pataquia (não se justifica a escritura com k), patarra, pecuniarda, perozil são para nós inteiramente estranhos, o que não quer dizer, evidentemente, que alguém não os tenha adoptado. Pataco, sobretudo no plural, tem sido muito empregado através dos tempos, desde que apareceu a moeda com tal nome, no valor de dois vinténs ou quarenta reis: usase especialmente na expressão não valer um pataco. Paus é possivelmente o vocábulo mais popular e familiar de todos os da lista; o significado, como toda a gente sabe, não é o de dinheiro, mas sim o de escudos: quinhentos paus era há pouco muito dinheiro. Pé 
de meia e o seu sinónimo pecúlio indicam dinheiro, sim, mas junto, geralmente com trabalho e sacrifício. Pecúnia, embora latinismo, é largamente familiar. Pesante tem aspecto de calão (= que pesa, logo moedas), e não nos lembramos de ouvi-lo. Pinto era o nome de uma moeda portuguesa (igual a 480 reis), mas jamais nos apareceu como sinónimo de dinheiro. Portuguesa é o termo que só conhecemos como designação, usada em especial no estrangeiro (por exemplo em França), de antiga e valiosa moeda de ouro (além de designar uma variedade de ostra exportada pelo nosso país), como existia também a lisbonnine, de origem bem clara. Prata como sinónimo de dinheiro é evidente, mas não corrente, pelo menos no nosso tempo.

No Q, quantia é sobejamente conhecido, mas para indicar uma porção de dinheiro: pequena ou grande quantia; há quem diga mesmo uma quantia de dinheiro! Na letra R, riqueza é bem sinónimo de dinheiro, lato sensu; quanto a roço é por nós ignorado, mas vem registado no Dicionário da Língua Portuguesa da Porto Editora. No S, sapecas e as suas variantes designam uma moeda chinesa, furada no centro, mas não as conhecemos como indicativas da ideia de dinheiro. T: nunca ouvimos taca, mas sabemos que é popular para dinheiro. V: vintém (=20 reis) usa-se actualmente nas expressões não ter vintém (não ter dinheiro algum) e ter o seu vintém (o contrário), além do composto trêsvinténs, de significado anatómico bem popular. No Z, zezulho e zimbo são-nos desconhecidos em Portugal, mas o segundo indica certa concha adoptada como moeda no Congo.

Para encerrar este modesto trabalho (aliás extremamente facilitado pela valiosa lista que utilizámos), propomo-nos agora apontar mais alguns termos relacionados com dinheiro, de que tivemos (ou temos) conhecimento durante a nossa já longa vida.

Infelizmente só nos ocorrem os seguintes: bagunça (mais usado no sentido de confusão), carcanhóis, coroas, maçaroca (semanticamente ligado a milho), óbolo (sobretudo no sentido de pequena esmola), pilim (muito popular), tostão e tostões (este no sentido lato de dinheiro) e tusto (plural tustos), deturpação de tostão e tostões, em gíria.

Não queremos acabar sem deixar aqui mencionada esta conhecida frase sinónima de dinheiro: aquilo com que se compram os melões!

Julgamos, em particular para os estrangeiros estudiosos da nossa língua, sobretudo os interessados em traduções e em gíria ou calão, que esta pequena contribuição, que podemos considerar mista (por ser de um anónimo de há sessenta anos e parcialmente nossa) poderá ser de alguma utilidade.

\section{O IZRAZIH ZA DENAR}

V svojem prispevku avtor Fernando Venâncio Peixoto da Fonseca obravnava različne izraze za denar. Izhaja iz otroške priloge $O$ Tiroliro revije $A$ Voz, ki je izhajala pred šestdesetimi leti. $V$ enem od člankov v tej prilogi $z$ dne 27. avgusta 1939, v številki 525 na strani 5, je anonimni avtor, ki se je podpisal Zé, objavil seznam izrazov za denar. Avtor pričujočega članka povzema te izraze in jih kritično komentira. Na koncu doda nekaj novih izrazov za denar, ki jih ni v seznamu, so pa v rabi v današnji portugalščini. 